\title{
Taking action to avoid recurring risks in medical professional liability claims
}

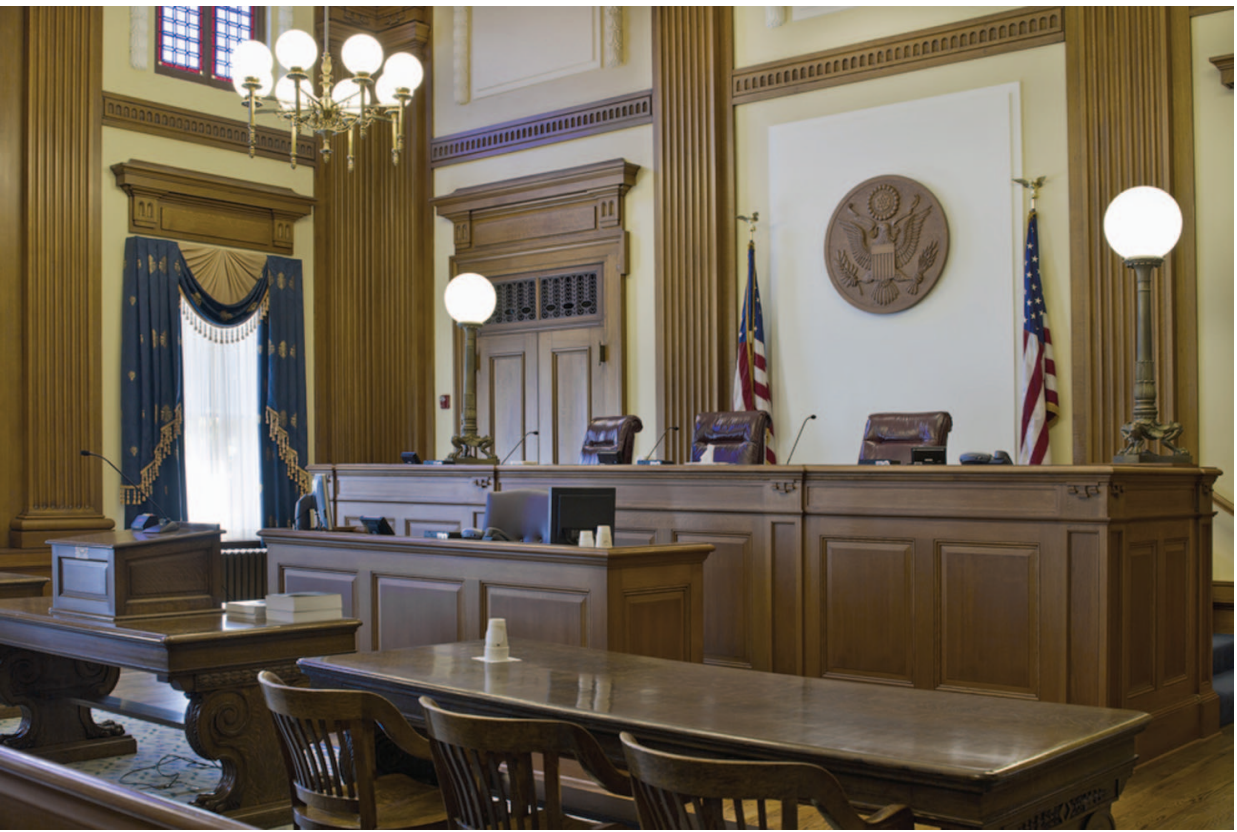

Jacqueline M. Melonas, RN, MS, JD*

Ann L. McNary, JD*

Address correspondence and reprint requests to Jacqueline $\mathrm{M}$. Melonas, PRMS, Inc., 1515 Wilson Blvd., Suite 800, Arlington, VA 22209 melonas@prms.com

Neurology ${ }^{\circledR}$ Clinical Practice 2010;75(Suppl 1):S45-S51 duce the risk of being sued and, in the event of a lawsuit, to put neur . against allegations of malpractice.

THE PERFECT STORM If one is to believe the statistics put forth by various watch groups, significant errors occur every day, and yet, though on the rise, litigation statistics do not reflect these large numbers. Why is this? Before a lawsuit is even filed, a triumvirate of factors must come together to create the perfect storm: error or perceived error, an angry patient/plaintiff, and a physician who is susceptible to being sued.

Error or perceived error. Medicine is an imprecise science and errors occur. It is often as the result of error that medicine has advanced. It is ironic, therefore, that those advances in medicine that allow for improvements in patient care are often a double-edged sword as they also increase patients' expectations of a perfect result and perceptions that error has occurred when those perfect results are not achieved. Although an error or an otherwise unanticipated outcome does not necessarily equate to negligence, this is a concept that is often difficult for patients to grasp. To many a lay person, anything less than a perfect result is an error regardless of the reason and when faced with this situation they feel they should be entitled to compensation.

Angry patient/plaintiff. Historically, closed claims data have shown that claims against neurologists are twice as likely to stem from an initial consultation (typically occurring in a patient's hospital room) as they are from ongoing treatment. ${ }^{4}$ This suggests 2 things: the severity of the patient's condition in these cases is such that optimal results are difficult_-if not impossible — to obtain, and the nature of the encounter does not allow the neurologist to forge the type of trusting relationship with patients that would lessen the likelihood of a claim being filed. Combine a "bad" or unforeseen outcome with a patient (or patient's family) who has not had the time to develop trust in the treating physician and the result may be an angry individual who needs to focus blame on someone. Unfortunately, that someone often ends up being the physician. Regardless of the treat-

From PRMS, Inc., Arlington, VA.

*These authors contributed equally to this work.

Disclosure: Author disclosures are provided at the end of the article. 
ment setting or the length of the treatment relationship, however, when there are patients (or patients' family members) whose expectations regarding treatment have not been appropriately managed, there is always the potential for anger and frustration that all too often manifests itself in a claim or lawsuit.

Physician who is susceptible to a lawsuit. Experienced plaintiff attorneys will take into account several factors before agreeing to file a malpractice action. Obviously they will look at the patient's injuries and will review the medical facts of the case. They will also take a look at the physician and his or her patterns of practice. Is documentation thorough or are records scant? Does the physician appear to be current in his or her knowledge of treatment modalities? What systems did the physician appear to have in place within his or her office to support patient care? How was the relationship between physician and patient? Finally, what was the patient's perception of the physician's demeanor?

Analysis of medical malpractice claims and lawsuits reveals that the recurrent problems, or risks, that increase the probability of a lawsuit being filed are diagnostic errors, communication problems, and insufficient documentation. A physician cannot always control treatment outcomes nor can a physician necessarily avoid a patient who might prove to be litigious. However, by focusing on managing these recurring areas of risk, a physician can minimize his or her level of susceptibility to being sued.

\section{Take time to convey caring and concern to patients by establishing a respectful relationship}

MANAGING THE RISKS The strategies for reducing risk are straightforward but the application and the means may differ as the root causes of the risks are often multifactorial, depending, at least, on the patient, the physician, and the clinical setting. For example, an error in diagnosis stemming from a lack of information may be the result of a systems failure preventing access to critical patient records, a language barrier between physician and patient, limited time for a thorough interview or examination, a patient who is a poor historian, or a combination of several of these and other factors. Solutions must be approached from both the "sharp end" and the "blunt end" of health care. ${ }^{5}$

The following key risk management actions are effective in avoiding many of the allegations typically
Table $1 \quad$ Examples of allegations against neurologists in medical malpractice cases $^{a}$

Failure to adequately and properly diagnose the patient's medical condition

Failure to perform an appropriate patient assessment before prescribing treatment

Negligently prescribing and managing medications

Failure to explain the risks of the medications prescribed

Failure to teach the patient about the proper use and dangers of the drugs

Failure to prescribe proper and timely treatment for the patient's condition

Failure to inform and warn of the risks involved in or associated with the patient's condition

Failure to inform the patient of the alternatives to and risk and potential consequences of the defendant's choice of

treatment of the patient

a Source: Professional Risk Management Services, Inc. (PRMS). PRMS manages The Neurologists' Program (TNP), a medical professional liability insurance program for neurologists. TNP is endorsed by American Academy of Neurology.

made against neurologists in medical professional liability claims (table 1).

I. Gathering sufficient information
A. About the patient
B. About the condition and treatments

II. Communicating
A. With the patient
B. With physicians and other treatment team members
C. With family members
A. Informed consent
B. Assessment and ongoing monitoring
C. Care and clinical decision-making (figure).

III. Documenting

GATHERING INFORMATION About the patient. It has been reported that "the rate of diagnostic error in medicine is likely to be in the range of 5\%-15\%." According to data from the Physician Insurers Association of America, between 1985 and 2009, failure to diagnose was the most frequent allegation made in neurology claims ${ }^{7}$ and "diagnostic interview, evaluation and consultation" 7 was listed as the procedure that most frequently led to claims being filed against neurologists. Gathering critical information to perform an adequate history and examination is crucial to reducing this risk.

The collection of critical information requires utilizing all available sources of information about the patient. In fact, expert witnesses in malpractice cases will criticize any failure to obtain, or failure to attempt to obtain, current and past patient and treatment information. Electronic health records (EHR) 


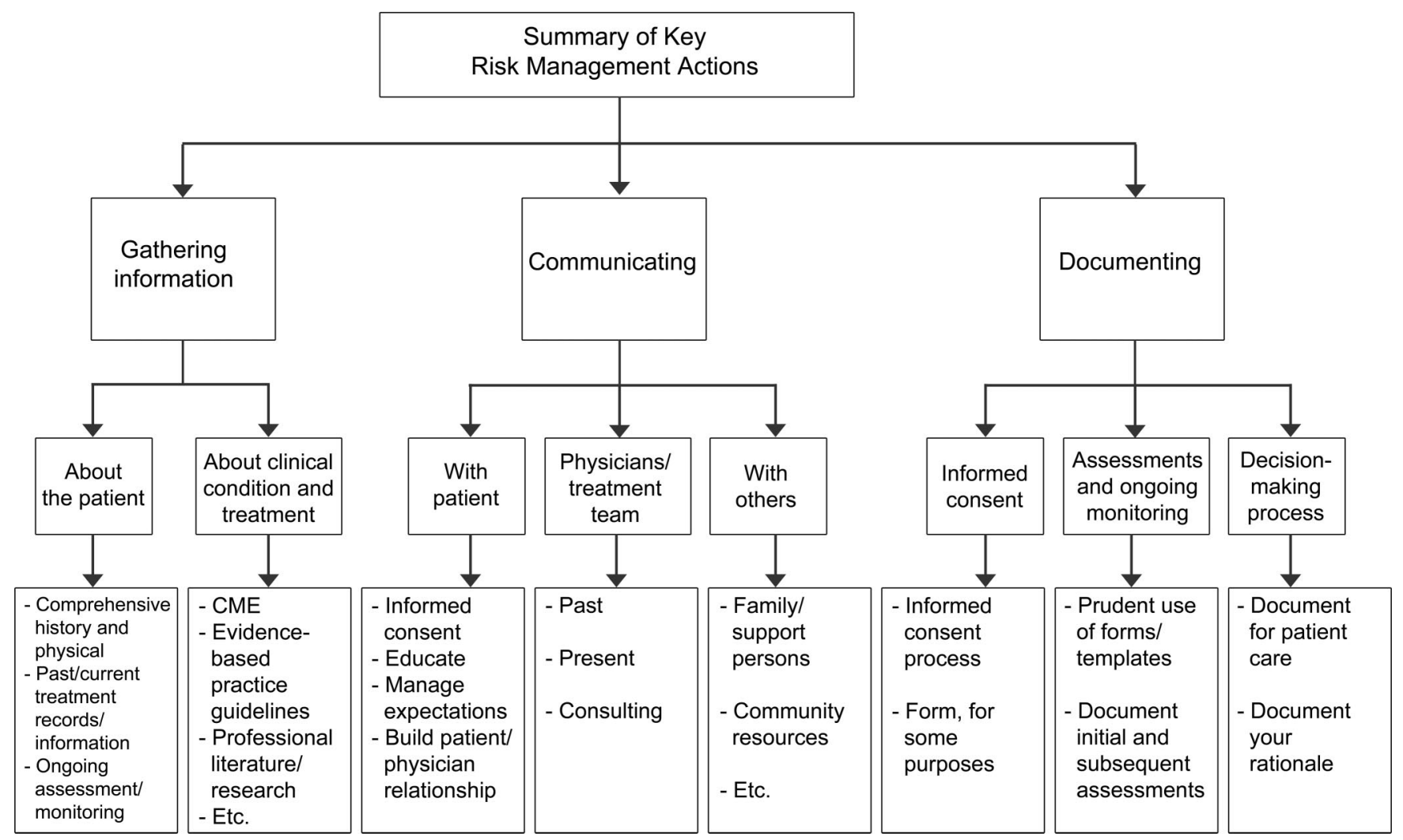

Adapted from a seminar developed and presented by Professional Risk Management Services, Inc.: High Risk Malpractice Liability Exposure, Risk Management and You. Excess Medical Malpractice Risk Management Seminar Pursuant to New York Insurance Department Regulation 124; March 26, 2010; New York, NY.

have the potential to improve access to and completeness of patient information. Other systemsbased solutions for reducing diagnostic error are not prevalent at this time because "diagnostic errors are often seen as cognitive errors rather than systems errors, and this perspective has perpetuated the view that individual physicians are to blame and systemsoriented solutions do not apply." ${ }^{8} \mathrm{New}$ EHR solutions ${ }^{9}$ hold the promise of reducing medical malpractice actions given that diagnostic errors result in more adverse events than do medication errors and are more likely to result in tort claims with high payouts. ${ }^{8}$

A standardized checklist of sources of patient information can be used by a physician and support staff to avoid overlooking routine sources of patient information and as a basis for documenting all attempts to obtain records/information. Use of patient engagement tools, such as those available from the $\mathrm{Na}$ tional Patient Safety Foundation, ${ }^{10}$ have the potential to improve the information from patients and families about current symptoms and past medical history, support effective physician-patient communication, and increase patient adherence to treatment.

A system to track and respond to test results is essential for ongoing monitoring and treatment plan- ning for the patient. Recent studies found that failure to inform patients of abnormal test results occurred at a rate of $7 \%$, with a range of $0 \%$ to $26 \%,{ }^{11}$ and that imaging tests with clinically significant abnormal results did not receive timely follow-up. ${ }^{12}$ Systems solutions, like the use of EHR and other health information technology (HIT), and good interpersonal communication among caregivers have the potential to help manage the increasing volume of test results ${ }^{13}$ and support patient safety.

About the condition and the treatment options. Problems in medical malpractice lawsuits are not usually a result of lack of knowledge. However, physicians who can be portrayed by a plaintiff attorney as not up-to-date with current literature/practices will be more vulnerable to assertions that they are not currently competent in their areas of practice.

James C. Johnston, MD, JD, ${ }^{14}$ recommends a reasonable approach to avoiding risk connected with the "most prevalent patient conditions generating suits against neurologists" 14 and discusses management strategies for stroke, epilepsy, and headache. ${ }^{14}$ The article is a good resource for neurologists and includes practical medical and legal advice, along 
with methodologies for avoiding diagnostic error, e.g., the use of the mnemonic SIGNAL to remember warning signs of secondary headache. ${ }^{14}$

Use of evidence-based practice guidelines is good medical practice, contributes to patient safety, and reduces medical professional liability risk. Although practice guidelines do not by themselves definitively establish the standard of care, they are used by both parties in litigation as evidence: plaintiffs to show that the defendant failed to observe standards of practice and defendants to show that they did observe standards of practice. ${ }^{15}$

The greater ability to access information provided by current technology presumes that the information will be accessed. The challenge is to access emerging knowledge within the constraints of practice and life demands. HIT allows for more immediate and convenient access to continuing medical education and up-to-date professional information. For example, clinical decision-making systems, peer-reviewed literature, drug databases, practice guidelines, access to authoritative medical information, and continuing education credits are possible via EHR systems, computers, and smart phones. However, unintended consequences of technology must be considered so as not to increase malpractice risk or jeopardize patient safety. ${ }^{16}$ One example of this is "alert fatigue" from poorly implemented computerized physician order entry (CPOE) systems that generate excessive numbers of drug safety alerts. This may cause physicians to ignore even important alerts and to override them, potentially impairing patient safety. ${ }^{17}$ Similarly, an EHR audit trail of ignored alerts "may serve as compelling proof of physician wrongdoing for plaintiffs who suffer poor outcomes because of a doctor's treatment decision." 16

COMMUNICATING With the patient and family. As the majority of malpractice claims against neurologists stem from initial contacts, effective communication is critical in avoiding risk. Additionally, good rapport and effective communication with all patients, long-term or for a one-time consult, can improve outcomes and decrease lawsuits. ${ }^{18,19}$ Various barriers to communication, such as health literacy concerns, must be addressed when they are present.

\section{CASE SCENARIO}

A patient with a history of hypertension presented to the ED, having suffered an apparent stroke. A CT scan revealed ischemic stroke. After the potential risks and benefits were discussed with her family, tissue plasminogen activator ( $P$ PA) was given. The patient subsequently developed an intracerebral hemorrhage, which produced permanent speech impairment and difficulty with walking. A suit was filed alleging that $t P A$ should not have been administered given her history. The jury determined that the family had been told of the potential risks and had willingly given consent. The jury found in favor of the defendant.
The informed consent process presents an opportunity to educate, manage patient (and family) expectations about treatment, improve treatment outcomes, increase adherence to the treatment plan, and reduce risk- both clinical and legal. Certain clinical situations may create a barrier to informed consent communications, e.g., when evaluating a patient for treatment of acute stroke in the emergency department (ED), where the neurologist is seeing the patient and family for the first time and there is limited time and opportunity to develop the physicianpatient relationship. ${ }^{20}$

Other barriers may hamper communication, including informed consent discussions, with patients. Limited English Proficiency (LEP) and physical or cognitive impairments may require additional efforts by the clinician to ensure effective communication with patients. ${ }^{21}$ This has implications not only for patient safety and malpractice risk but also for regulatory compliance. ${ }^{22}$

Patients and their family members often feel a sense of fear and loss when a patient is diagnosed with a disease and they are forced to leave their familiar existence and suddenly learn a new language and to navigate the health care system. Physicians who stand ready to act as both interpreter and guide will not only greatly aid their patients but also help to insulate themselves from malpractice exposure.

With other physicians and the treatment team. Another important communication for patient safety is consultation with colleagues (formal or informal), especially for complex clinical presentations. This supports thoughtful decision-making and provides some assurance that the quality of care delivered meets the standard of care. Also, transitions in care are times of potential high risk for patients if handoff communications are lacking. ${ }^{23}$ During handoff communications, meticulous attention to communication with all providers who are involved with the patient is critical to support patient safety and the best outcomes possible. ${ }^{24}$ Standardized approaches, like the Situation, Background, Assessment, and Recommendation (SBAR) process, checklists, and technology solutions such as computerized sign-out systems are some of the best practices being used to reduce this risk. ${ }^{5}$

DOCUMENTING Physicians concerned with medical professional liability risk frequently ask exactly what should be documented in the patient record. It is helpful to think about documentation in terms of why instead of just what. Boiled down to the fundamentals, adequate documentation allows another clinician to review the record and know what occurred during treatment and why. For treatment purposes 
Table 2 Functions of an adequate medical record ${ }^{a}$

An adequate record:

- Substantiates clinical judgment and choices

- Demonstrates the knowledge and skill exercised during treatment

- Provides a contemporaneous assessment of the patient's needs and behaviors

- Documents significant events, revisions to the treatment plan, and explanations of decisions

a Adapted from a seminar developed and presented by Professional Risk Management Services, Inc.: High Risk Malpractice Liability Exposure, Risk Management and You. Excess Medical Malpractice Risk Management Seminar Pursuant to New York Insurance Department Regulation 124; March 26, 2010; New York, NY.

and when it comes to malpractice risk, the information about what actions were not taken is just as important as the information about what actions were taken. Documentation that provides subsequent readers with information about the basis of the physician's clinical decision-making process supports the argument that the physician exercised reasonable professional judgment should treatment decisions ever be challenged and, thus, decreases the physician's susceptibility to being sued. This is particularly true when it comes to the decision to deviate from an evidence-based practice guideline or to prescribe medication for off-label use. Ultimately, there is no such thing as a perfect record; however, an adequately documented record which serves clinical purposes will also suffice to protect the physician in the event of litigation (table 2).

In addition to the aforementioned, plaintiff attorneys in reviewing medical records and contemplating whether to accept a malpractice case will look for other signs that the patient may have received less than adequate treatment. As a physician will be expected to have a greater understanding of the ramifications of a patient's failure to follow treatment recommendations and thus will have the burden of attempting to increase the patient's adherence, a plaintiff attorney will look to see what efforts the physician made at such things as following up on missed or cancelled appointments, obtaining the patient's informed refusal for treatment, adequately documenting the physician's (and the patient's) decision to terminate care, and prescription refills. Did the physician document to enhance his or her own actions by pointing fingers at other providers, creating late or self-serving entries or even altering records? Is there any indication that the physician failed to convey laboratory or other test results or to document phone calls, thus suggesting a lack of effort toward ongoing communication with the patient?
EHR and other health information technologies have already shown benefits for clinicians and patients but unintended consequences of the new technology, among them issues relating to documentation, should be recognized. ${ }^{16}$ Some commentators have coined the term "e-iatrogenesis," defined as "patient harm caused at least in part by the application of health information technology." ${ }^{25}$ For example, physicians have been advised to beware of the dangers of use of the "copy and paste" function that leads to old and/or inaccurate clinical information being perpetuated and relied upon in the record. As physicians are responsible for their documentation, whether paper or electronic, they must make efforts to have input into needed improvements in EHR and health information technology that meets both their needs and those of their patients and eliminates or reduces unintended consequences and therefore, risk.

Documenting informed consent. Documentation of informed consent bears special consideration as allegations of lack of informed consent may be brought against a physician absent a finding or even an allegation of negligence. Even if the consequence suffered by the patient was a known risk of treatment, without adequate documentation of the education/ decision-making process, it can be difficult to prove that the patient or substitute decision-maker was informed and understood the material risks and benefits of the recommended treatment. Documentation of the patient or substitute decision-maker's response, questions, and the physician's input supports that a straightforward and truthful discussion took place and that the consent given was informed. For certain treatments the use of a signed consent form is required under state law, although this document should not be relied upon as the sole evidence of the patient's consent. However, even if not required, the use of a consent form may be useful to focus the decision-maker's attention on what he or she is consenting to, making it less likely that he or she will later believe that informed consent was not adequate.

CONCLUSION Just as patients facing disease are eager for a cure, physicians facing malpractice exposure want an antidote to the problem. Unfortunately, as with patients and disease, there is no magic pill or one-size-fits-all solution.

It is important to remember, however, that an adverse outcome does not mean medical care was negligent. A neurologist will be evaluated upon whether he or she met the standard of care, i.e., what a reasonable and prudent neurologist would do in the same situation. Physicians are advised to get the information needed to adequately assess, diagnose, and develop a treatment plan, and modify it as needed 
based on the continuing monitoring of the patient; and to know the applicable evidence-based practice guidelines. Take time to convey caring and concern to patients by establishing a respectful relationship. Use the informed consent process to educate patients, engage them in treatment, and manage expectations of what they can anticipate from treatment. Be sure to get credit for what you have done and why you have done it by adequately documenting in the patient record.

Utilize HIT, checklists, and other patient safety strategies to make system changes that improve patient safety and reduce risk. Avoid the risks in emerging technologies by staying informed and involved in their development. Draw on key risk management actions to support patient safety and reduce medical professional liability risk and take advantage of opportunities to be involved in patient safety initiatives in your practice setting and through professional organizations, such as the American Academy of Neurology.

\section{DISCLOSURE}

J.M. Melonas is a full-time paid employee of Professional Risk Management Services, Inc. and the manuscript was written in the course of her employment. Professional Risk Management Services, Inc. manages The Neurologists' Program (TNP), a medical professional liability insurance program. TNP is endorsed by the American Academy of Neurology. A.L. McNary is a full-time paid employee of Professional Risk Management Services, Inc. and the manuscript was written in the course of her employment.

Received July 2, 2010. Accepted in final form September 9, 2010.

\section{REFERENCES}

1. Pozgar GD. Legal Aspects of Health Care Administration, 10th ed. Sudbury: Jones \& Bartlett; 2007.

2. Studdert DM, Mello MM, Gawande AA, et al. Claims, errors, and compensation payments in medical malpractice litigation. N Engl J Med 2006;354:2024-2033.

3. Cranberg LD, Glick TH, Sato L. Do the claims hold up? A study of medical negligence claims against neurologists. J Empirical Legal Stud 2007;4:155-162.

4. MacReady N. From an analysis of malpractice claims: strategies to enhance patient safety, reduce litigation risk. Neurol Today 2006; Mar 7:14-15.

5. Wachter RM. Understanding Patient Safety. New York: McGraw-Hill; 2008.

6. Graber ML. Educational strategies to reduce diagnostic error: can you teach this stuff? Adv Health Sci Educ 2009; 14:63-69.

7. Physician Insurers Association of America. Risk Management Review (Neurology). Rockville, MD: PIAA; 2009.

8. Newman-Toker DE, Provonost PJ. Diagnostic errors: the next frontier for patient safety. JAMA 2009;301:1060-1062.

9. Schiff GD, Bates DW. Can electronic clinical documentation help prevent diagnostic errors? N Engl J Med 2010; 362:1066-1069.

10. National Patient Safety Foundation. Patient engagement tools: Patient safety awareness week: "Working with your doctor or nurse to get the right diagnosis" and "The uni- versal patient compact: principles for partnership." Available at: www.npsf.org. [See also "Ask Me 3: Good questions for getting the right diagnosis," part of the Ask Me 3 Patient Safety Series. Available at: www.npsf.org/ askme3.] Accessed August 15, 2010.

11. Casalino LP, Dunham D, Chin MH. Frequency of failure to inform patients of clinically significant outpatient test results. Arch Intern Med 2009;169:1123-1129.

12. Timely follow-up of abnormal diagnostic imaging test results in an outpatient setting. Arch Intern Med 2009;169:15781586.

13. Singh H, Vij M. Eight recommendations for policies for communicating abnormal test results. Jt Commission J Qual Patient Safety 2010;36:226-232.

14. Johnston JC. Neurological malpractice and nonmalpractice liability. Neurol Clin 2010;28:441-458.

15. Professional Risk Management Services, Inc. Examiner's perspective: treatment guidelines. Rx for Risk 2003;11:3.

16. Hoffman S, Podgurski A. E-health hazards: provider liability and electronic health record systems. Berkeley Technology Law J 2009;24:1523-1582.

17. The Joint Commission. Safely implementing health information and converging technologies: Sentinel Event Alert; Issue 42: December 11, 2008. Available at: http://www. jointcommission.org/SentinelEvents/SentinelEventAlert/ sea_42.htm. Accessed August 16, 2010.

18. Levinson W. Physician-patient communication: a key to malpractice prevention. JAMA 1994;272:1619-1620.

19. Levinson W, Roter DL, Mullooly JP, et al. Physicianpatient communication: the relationship with malpractice claims among primary care physicians and surgeons. JAMA 1997;277:553-559.

20. White-Bateman SR, Schumacher HC, Sacco RL, Appelbaum PS. Consent for intravenous thrombolysis in acute stroke: review and future directions. Arch Neurol 2007;64: 785-792.

21. Bartleson JD. How to be sure your patient education is educating patients. Available at: http://www.aan.com/ globals/axon/assets/6106.pdf. Accessed August 20, 2010.

22. For more information on the Americans with Disabilities Act (ADA) requirements, see US Department of Justice resources available at www.ada.gov and American Medical Association information available at www.ama-assn.org. For more information on LEP requirements, see U.S. Department of Health and Human Services resources available at www.hhs.gov/ocr/ civilrights/resources/specialtopics/lep/index.html and www. hrsa.gov/publichealth/healthliteracy/ (online training). Accessed September 5, 2010.

23. Parker J. Patient safety weekly blogs: day 3 , handoff communications. The Joint Commission 2009. Available at: fhttp://www.jcrinc.com/Blog/2009/3/9/Patient-SafetyWeek-Blogs-Day-3-Handoff-Communications/. Accessed August 23, 2010.

24. World Health Organization, Collaborating Centre for Patient Safety Solutions. Communication during patient handovers. WHO Press [serial online]. 2007;1:1-4. Available at: http://www.ccforpatientsafety.org/common/pdfs/fpdf/ presskit/PS-Solution3.pdf. Accessed July 6, 2010.

25. Weiner JP, Kruri T, Chan K, Fowles JB. Comment: "e-Iatrogenesis": the most critical unintended consequence of $\mathrm{CPOE}$ and other HIT. J Am Med Inform Assoc 2007:14:387-388. 


\section{ADDITIONAL RESOURCES}

DesRoches CM, Campbell EG, Vogeli C, et al. Electronic health records' limited successes suggest more targeted uses. Health Aff 2010;29:639-646.

Gawande A. The Checklist Manifesto: How To Get Things Right. New York, NY: Metropolitan Books, Henry Holt and Company; 2009.

Glick TH. The neurologist and patient safety. Neurologist 2005;11:140-149.

Hickson GB, Federspiel CF, Pichert JW, Miller CS, Gauld-Jaeger J, Bost P. Patient complaints and malpractice. JAMA 2002;287:2951-2957.

Kane CK. Medical liability claims frequency: A 2007-2008 snapshot of physicians. Policy Research Perspectives, American Medical Association 2010. Available at: http://www.ama-assn.org/ama1/pub/upload/mm/363/prp-201001-claim-freq.pdf. Accessed September 1, 2010.

Liang BA, Lew R, Zivin JA. Review of tissue plasminogen activator, ischemic stroke, and potential legal issues. Arch Neurol 2008;65:1429-1433.

Thiess DE, Sattin JA, Larriviere DG. Hot topics in risk management in neurologic practice. Neurol Clin 2010;28:429-439.

\section{If you liked this article, you may be interested in. . . \\ Neurology \\ A. DePold Hohler, et al. Invited Article: Improving safety for the neurologic patient: Evaluating medications, literacy, and abuse. Aug 24, 2010; www.neurology.org}
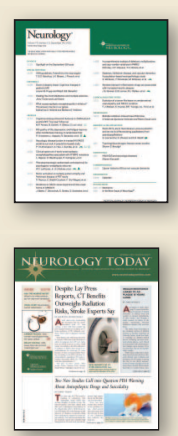

\section{Neurology Today}

Orly Avitzur. Mitigating Risk: What Neurologists Should Know to Reduce Med-Mal and Other Liability Exposure. February 21, 2008; www.neurotodayonline.com

Elizabeth Stump. How to Avoid Malpractice Risks When Prescribing Off-Label. October 16, 2008; www.neurotodayonline.com

Orly Avitzur. The Ordeal of Medical Malpractice Lawsuits: Even When You Win You Lose. February 18, 2010; www.neurotodayonline.com 


\title{
Neurology
}

\author{
Taking action to avoid recurring risks in medical professional liability claims \\ Jacqueline M. Melonas and Ann L. McNary \\ Neurology 2010;75;S45-S51 \\ DOI 10.1212/WNL.0b013e3181fc284c
}

This information is current as of November 1, 2010

$\begin{array}{ll}\begin{array}{l}\text { Updated Information \& } \\ \text { Services }\end{array} & \begin{array}{l}\text { including high resolution figures, can be found at: } \\ \text { http://n.neurology.org/content/75/18_Supplement_1/S45.full }\end{array} \\ \text { References } & \text { This article cites } 16 \text { articles, } 0 \text { of which you can access for free at: } \\ \text { http://n.neurology.org/content/75/18_Supplement_1/S45.full\#ref-list-1 } & \\ \text { This article, along with others on similar topics, appears in the } \\ \text { following collection(s): } \\ \text { Error in medicine } \\ \text { http://n.neurology.org/cgi/collection/error_in_medicine } \\ \text { Malpractice } \\ \text { http://n.neurology.org/cgi/collection/malpractice } \\ \text { Patient safety } \\ \text { http://n.neurology.org/cgi/collection/patient_safety } \\ \text { Information about reproducing this article in parts (figures,tables) or in } \\ \text { its entirety can be found online at: } \\ \text { http://www.neurology.org/about/about_the_journal\#permissions } \\ \text { Permissions \& Licensing } \\ \text { Information about ordering reprints can be found online: } \\ \text { http://n.neurology.org/subscribers/advertise }\end{array}$

Neurology ${ }^{\circledR}$ is the official journal of the American Academy of Neurology. Published continuously since 1951, it is now a weekly with 48 issues per year. Copyright Copyright $@ 2010$ by AAN Enterprises, Inc.. All rights reserved. Print ISSN: 0028-3878. Online ISSN: 1526-632X.

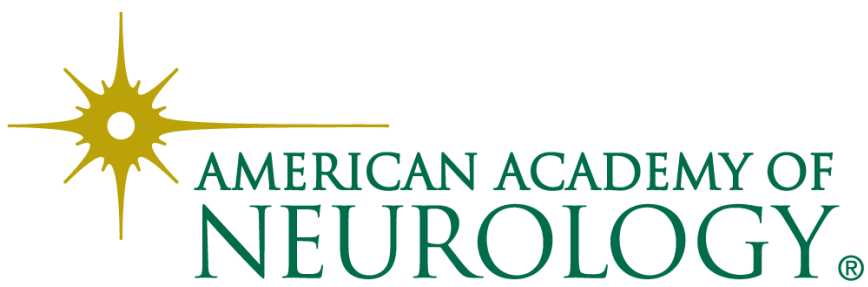

